\title{
Selected aspects of electricity generation in a private photovoltaic installation
}

\author{
Krzysztof Przystupa ${ }^{1}$ \\ ${ }^{1}$ Lublin University of Technology, Department of Automation, Nadbystrzycka 36, 20-618 Lublin, Poland
}

\begin{abstract}
The article discusses basic types of photovoltaic modules and their use in various configurations of home power plants. The astronomical conditions and estimation of intensity of solar radiation outside the Earth's atmosphere as a factor determining the scope of electricity production are described. The construction of a stationary photovoltaic installation with a capacity of $4.16 \mathrm{~kW}$, consisting of 16 polycrystalline photovoltaic panels cooperating with the Fronius inverter is presented. Subsequently, 7 very similar installations were analysed. It was ensured that: analysed installations were oriented southwards with a maximum 2-minute deviation, an angle of panels was similar and ranged from 35 to $38^{\circ}$. Installations have been installed in the same geographical area, at a short distance from one another. Energy produced was monitored during a monitoring of an electricity production process. In an empirical part of this article, energy yields obtained in 2017 are shown. Based on collected data, the analysis showing selected aspects of production, including its repeatability in analysed periods of time, was conducted. Obtained data and mathematical relationships allow to develop models for prediction and diagnostics of plant performance.
\end{abstract}

\section{Introduction}

Photovoltaic systems can be divided according to their methods of generated electricity utilisation, and according to a way of cooperation with the local power grid. Off-grid systems operate autonomously, i.e. completely outside the network, while on-grid systems i.e. systems that are connected to and cooperate with the public power grid, and systems that are connected to but do not cooperate with the public power grid [1-2].

\section{Photovoltaic modules}

Another division results from a type of photovoltaic modules used (installations with monocrystalline, amorphous, polycrystalline modules, etc.). The most popular modules for construction of home solar power plants are made of silicon cells. Their structure may be monocrystalline (efficiency 18-25\%); yet currently the market of small power plants (up to $10 \mathrm{~kW}$ ) is dominated by modules with polycrystalline structure, with lower efficiency (c.a. 14-20\%). Monocrystalline modules are relatively cheap. Both polycrystalline and monocrystalline cells are made of silicon wafers with thickness of about $0.1-0.3 \mathrm{~mm}$. Types of modules described are so-called first-generation cells - that is, older solutions, but they are still used. Their characteristic feature is greater thickness [3-6]. Obviously, one can also find other types of modules, including interesting functional properties. For example, amorphous modules are made in completely different technology, carried out by sputtering, vapor deposition or epitaxy (a process of growth of monocrystalline semiconductor layer on a monocrystalline substrate), resulting in very thin silicon layers (c.a. $1-2 \mu \mathrm{m}$ ). This type of modules is used primarily in buildings with a glass façade or with a glass roof. This is due to the fact that they can be applied onto glass, reducing insolation and preventing overheating of rooms. Based on this type of cells, building integrated systems (Building Integrated Photovoltaics BIPV) are built [7]. They are less applicable due to inferior performance features, inter alia related to frequent occurrence of the Staeblera-Wronski effect, which causes lower efficiency. A characteristic feature of these modules is their inability to indicate individual cells [8]. Newer photocell designs are not based on silicon, only on a mixture of different semiconductors, for example cadmium telluride (CdTe), cadmium sulphide (CdS), gallium arsenide (GaAs), indium phosphide (InP). These solutions are so-called second-generation cells - CISG cells based on copper, indium, gallium and selenium alloys [9]. The latest modules, i.e. third-generation modules, do not have $p-n$ semiconductor junction. At present, there are at least several types of such cells:

- focusing light cells,

- multi-junction semiconductor cells,

- cells with a dye,

- OPV organic cells,

- other cells, for example perovskite cells.

Modules built with the third-generation cells are currently not used much due to their still short working time and often low efficiency. 


\section{Astronomic conditions and estimating solar radiation}

Numerous publications discuss an influence of many factors on production of electricity by photovoltaic modules. Fig. 1. shows the most frequently analysed factors.

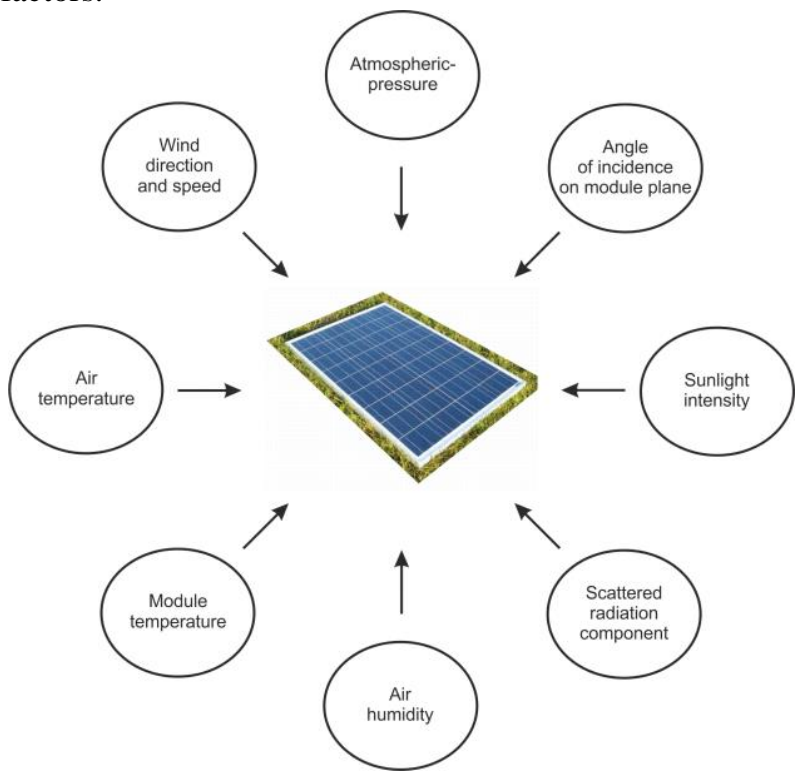

Fig. 1. Factors determining energy production in photovoltaic cells.

The analysis of dependence of electric energy production on atmospheric factors, widely discussed in the literature, showed strong relationships, expressed by the coefficient of determination from intensity of solar radiation $R^{2}=0.98$, and at constant solar radiation intensity from air temperature $R^{2}=0.69$, air humidity $R^{2}=0.30$, atmospheric pressure $R^{2}=0.15$, wind direction and velocity $R^{2}=0.003$, with a coefficient of determination of 0.003 in practice means no correlation [10-11]. It is obvious that the amount of energy produced is also directly proportional to the time of lighting the module, and thus the total value of intensity of solar radiation reaching it and it is variable due to the movement of the Earth around the Sun (Fig. 2.).

The full cycle of the Earth around the Sun takes 365 days 5 hours 48 minutes and 46.5 seconds. At this time, the value of solar radiation intensity changes from $1.33 \frac{\mathrm{kW}}{\mathrm{m}^{2}}$ in July, when a distance of the Earth from the Sun is the highest $\left(1.522 \cdot 10^{8} \mathrm{~km}\right)$ to $1.42 \frac{\mathrm{kW}}{\mathrm{m}^{2}} 2$ in January at distance of $1.472 \cdot 10^{8} \mathrm{~km}$.

Intensity of light together with the time resulting from the period between sunrise and sunset are basic factors to produce electricity in photovoltaic cells and modules. Fig. 3. shows variability of a day length defined as the time from sunrise to sunset as a function of a day number of a year, where No. 1 corresponds to January 1, and No. 365 corresponds to December 31.

Throughout the year, a latitude in which the Sun rises at a zenith is changing. The basis for determining dates of astronomical changes in seasons is the topping of the Sun at the zenith above the equator or tropics. These phenomena are accompanied by changes in the duration of day and night. Every moment of changing the season is determined by means of calculations and astronomical observations, and in fact every year falls out at a different time of the day or even on a different day. Therefore, for example, the beginning of spring sometimes falls not on $21^{\text {st }}$, but on $20^{\text {th }}$ or $22^{\text {nd }}$ of March. It is similar with the beginning of other seasons. The meteorological seasons have been established for the needs of meteorologists and climatologists to calculate statistical averages to compare always the same period. Because astronomical and thermal pores have "movable" dates, they are not suitable for this. In different countries, regions and institutions, meteorological times can have different time intervals.

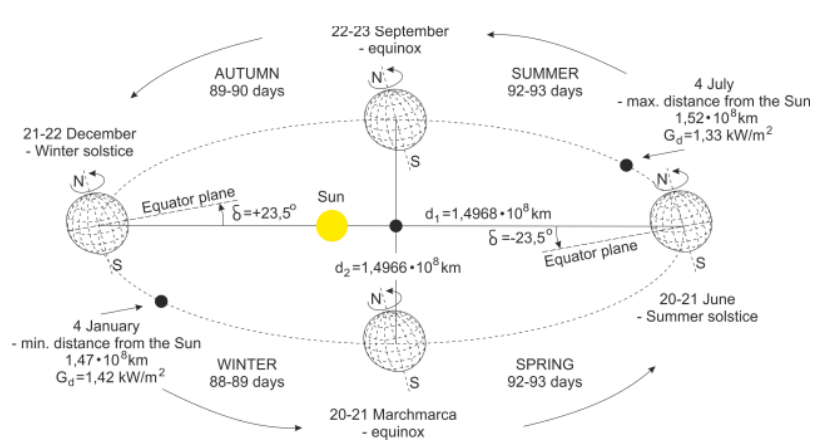

Fig. 2. Change in solar distance and declination because of the Earth's movement in an elliptical orbit around the Sun.

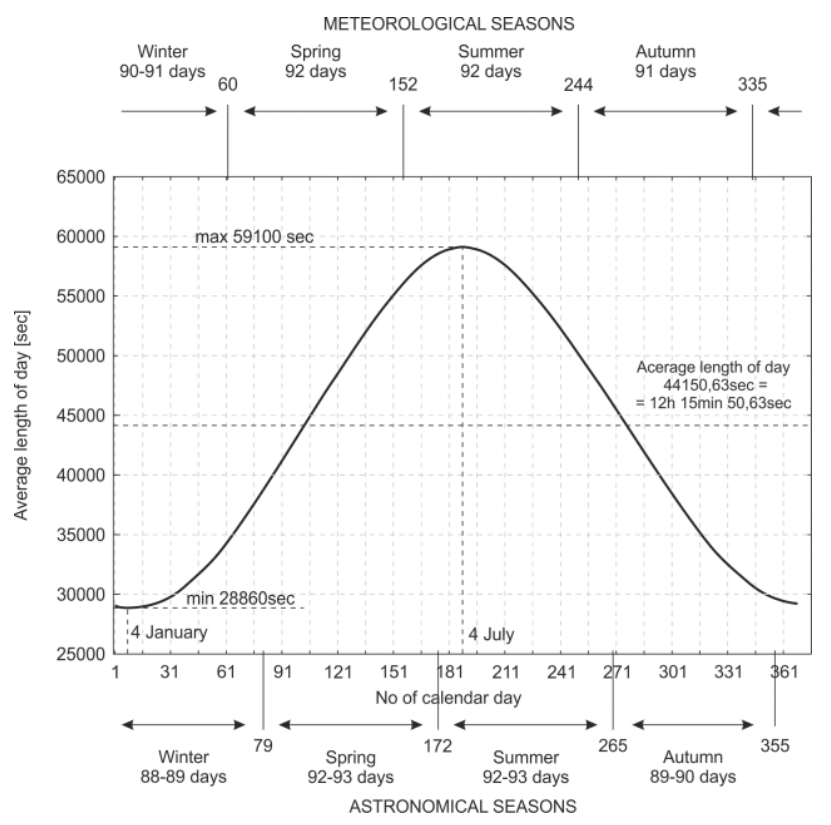

Fig. 3. Variation in a day length in a year.

An average value of intensity of solar radiation reaching the upper layers of the Earth's atmosphere at an average distance of the Earth from the Sun (1,495-108 km) is called the solar constant $I_{0}$ and is $1376 \frac{\mathrm{W}}{\mathrm{m}^{2}}$ [12]. However, its current value is described by the dependence: 


$$
\begin{aligned}
& G_{d}=I_{0}\left(1.00011+0.034221 \cos \alpha_{d}+\right. \\
& \left.0.00128 \sin \alpha_{d}+0.000719 \cos 2 \alpha_{d}+\right) \\
& \left.+0.000077 \sin 2 \alpha_{d}\right)
\end{aligned}
$$

where:

$\alpha_{d}=2 \pi(d-1) / 365-$ angle of the Earth's orbit around the Sun,

$\mathrm{d}$ - number of the day of the year [12].

The graphic image of this relationship is shown in Figure 4.

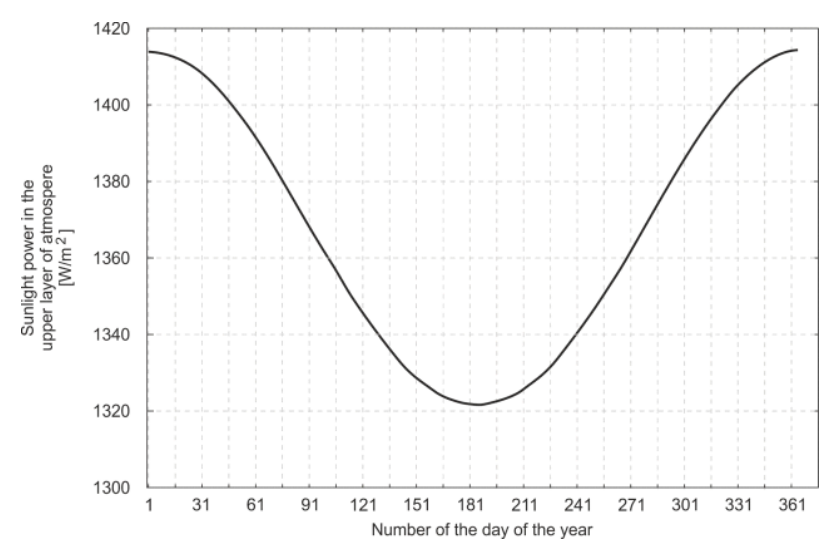

Fig. 4. Solar radiation power in the upper atmosphere layers as a function of the number of the day of the calendar year.

To approximate the results obtained to a real situation, an angle of direct light to a surface of solar modules should be considered (Fig. 5.).

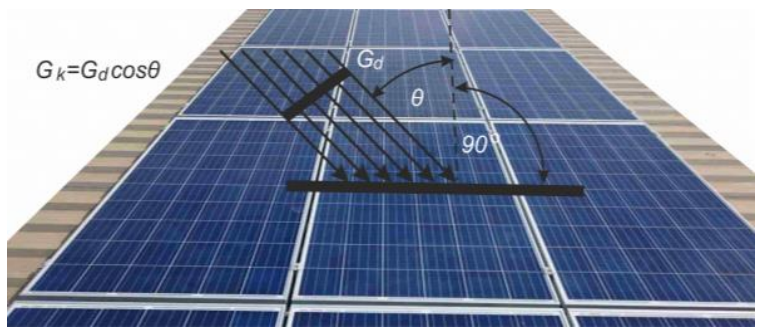

Fig. 5. Influence of the angle of incidence $\theta$ of solar rays with the intensity $G_{d}$ on the surface of the modules on the value of radiation intensity $G_{k}$.

The relationship specified in Figure 5. has the form:

$\theta=\cos ^{-1}(\cos (\varnothing-\gamma) \cos \delta \cos \omega+$

$+\sin (\emptyset-\gamma) \sin \delta)$.

where in:

$\delta=0.006918-0.399912 \cos \alpha_{d}+$

$+0.070257 \sin \alpha_{d}-0.006758 \cos 2 \alpha_{d}+$

$+0.000907 \sin 2 \alpha_{d}-0.002697 \cos 3 \alpha_{d}+$

$+0.00148 \sin 3 \alpha_{d}$,

where:

$\varnothing$-- latitude of a given location,

$\gamma$-slope angle of the module plane,

$\omega$ - value of the position angle of the Sun in the sky,

$\delta$ - angular position of the Sun at the astronomical south, relative to the equator plane [12].
Another disruption that must be considered to determine intensity of solar radiation on the Earth's surface is variable clarity of the atmosphere. It is considered by calculating a coefficient $K_{T}$, which is calculated for specific days of the so-called recommended days. Their dates have been collected in Table 1.

Table 1. Ordinal numbers of the day of year of recommended days.

\begin{tabular}{|c|c|c|c|c|c|}
\hline No. & Month & $\begin{array}{c}\text { The number of } \\
\text { recommended } \\
\text { days }\end{array}$ & No. & Month & $\begin{array}{c}\text { The number } \\
\text { of } \\
\text { recommended } \\
\text { days }\end{array}$ \\
\hline 1 & January & 17 & 7 & July & 198 \\
\hline 2 & February & 47 & 8 & August & 228 \\
\hline 3 & March & 75 & 9 & September & 258 \\
\hline 4 & April & 105 & 10 & October & 288 \\
\hline 5 & May & 135 & 11 & November & 318 \\
\hline 6 & June & 162 & 12 & December & 344 \\
\hline
\end{tabular}

The presented values of $G_{k}$ and $K_{T}$, of course, increase accuracy of calculations, but also considerably complicate a mathematical formula, however, they do not change the shape of curve, which maps an amount of energy supplied to the surface of the module. This shape is similar to that shown in Fig. 3. but has a smaller amplitude (it is a result of a product of values from Fig. 3. and Fig. 4., $\cos \theta$ and a coefficient of transparency of the atmosphere). In practice, this means that the amount of solar energy supplied to the modules is consistent with Fig. 6 and Fig. 7 At the same time, this is the value of insolation outside the atmosphere on a plane parallel to the Earth's surface.

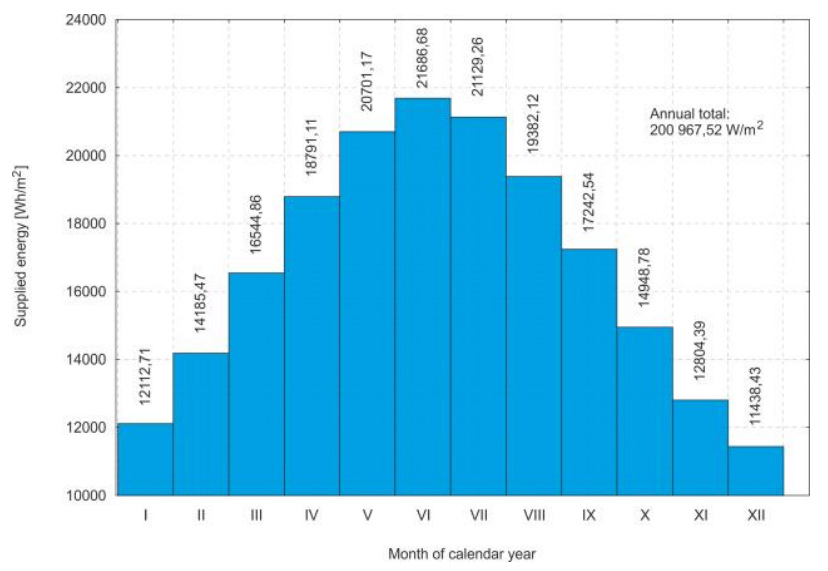

Fig. 6. Sunlight outside the atmosphere in each month of the calendar year.

Figure 6 shows that the sun exposure outside the atmosphere is normally distributed. In contrast, Figure 7. shows that the amount of energy delivered in three most favourable months is $41.4 \%$ and in six months it is as high as $72.8 \%$, which means $75 \%$ of energy is delivered within half a year. The largest amount of energy $(39.8 \%)$ reaches the Earth in meteorological summer, $32.1 \%$ in spring, while fall and winter only $28.1 \%$. 


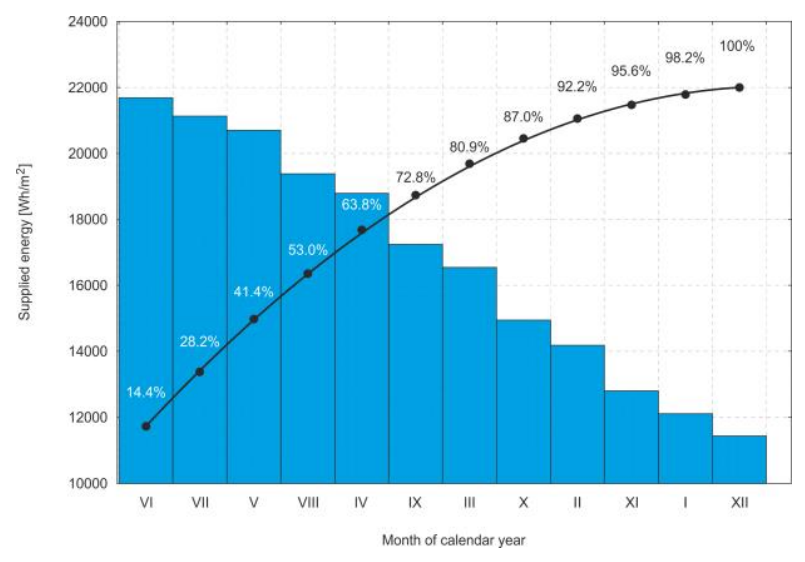

Fig. 7. Pareto-Lorenz diagram, sun exposure outside the atmosphere in months of the calendar year.

The results of the Pareto-Lorentz analysis suggest that if favourable spring and summer occur, in real conditions optimised on the surface of the Earth, these seasons can provide all planned annual production. An equally favourable situation occurs in the II and III quarters of the calendar year (38.5 and 34.3\%) and less favourable in I and IV quarter (15.9 and 11.4\%). This obviously translates into more favourable first half-year of the calendar year (54.4\%) and weaker second $(46.63 \%)$.

\section{Installation setup}

An object of an analysis is 7 micro photovoltaic installations. Relative positions of individual installations are shown in Figure 8. They were selected so that the distance between them was as small as possible.

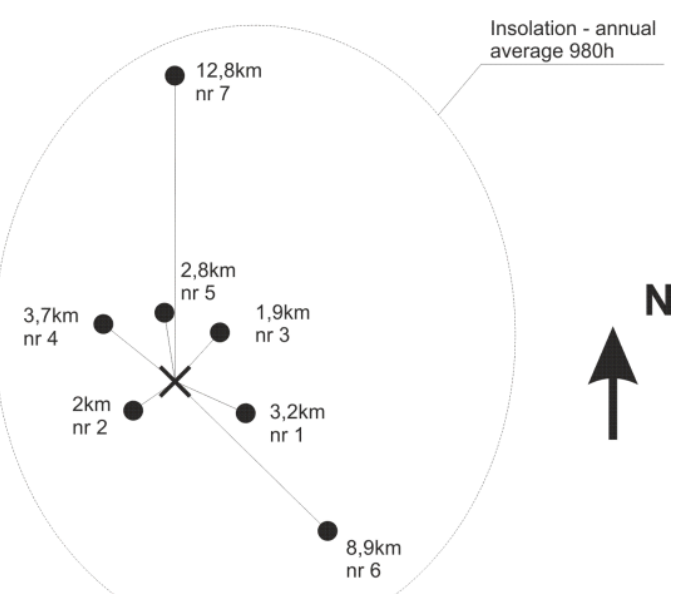

Fig. 8. Distribution of the analysed micro installations.

Installations were made using the Fronius Primo 4.01 inverter, each of the installations consists of 16 Sharp monocrystalline modules, each with $260 \mathrm{~W}$ power, configured in two identical rows with a total power of $4.16 \mathrm{~kW}$. The analysed installations were selected in such a way that deviation from the southern direction does not exceed more than \pm 2 angular minutes. However, the angle of inclination of modules was from 35 to $38^{\circ}$. Installations were built in the Mazowsze region based on a scheme in Fig. 9.

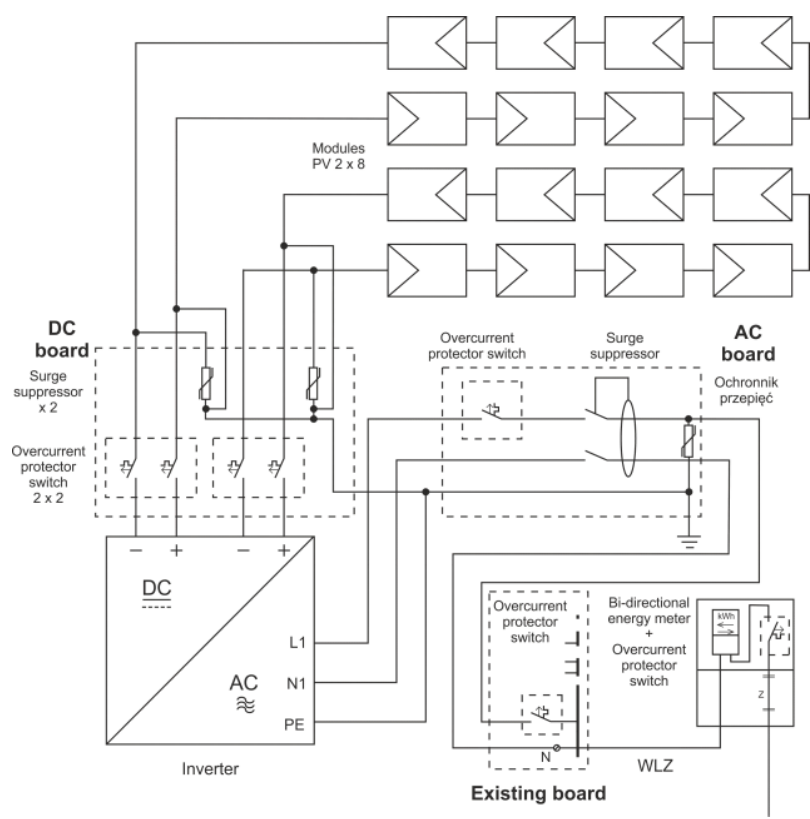

Fig. 9. Electrical diagram of photovoltaic installation.

The most important element of installation is an inverter. It is a transformer less electronic device, to which two series of photovoltaic modules can be connected. The series of modules must be constructed in such a way that a total DC voltage is in a range of 210$800 \mathrm{~V}$ for each series separately. Therefore, in the system, the DC voltage never exceeds $800 \mathrm{~V}$, and the AC voltage is $410 \mathrm{~V}$. This is one of the reasons for splitting installation boards into two (DC board and AC board). Both electrical systems (direct and alternating current) were protected with overvoltage limiters, overcurrent circuit breakers and a residual current circuit breaker. The electrical system has been made so as not to disturb an existing measuring system and existing electrical protections (existing TM) in any way. After setting up photovoltaic installation, this fact was reported to the energy company, which changed the energy meter and signed a prosumer contract with the client.

\section{Results of production}

The diagram in Fig. 9. does not show how to carry out the measurements for the needs of the conducted analyses. The measurements were carried out using a computer measuring card, a voltage divider and a current transformer from Ferranti and an electronic electricity meter. To monitor and register measurements, a measurement interface, that the inverter is equipped with, can be alternatively used.

The use of the measuring card gives the opportunity to measure and record all electrical quantities with high frequency - even tens of measurements per second, while the inverter interface takes measurements and records their average value every few minutes. Table 2 summarises the values obtained in periods of monthly intervals. 
Table 2. The results of electricity produced in monthly periods.

\begin{tabular}{|c|c|c|c|c|c|c|c|c|c|c|c|c|c|}
\hline \multirow{2}{*}{$\begin{array}{c}\text { No. of } \\
\text { installation }\end{array}$} & I & II & III & IV & V & VI & VII & VIII & IX & $X$ & XI & XII & $\begin{array}{c}\text { Annual } \\
\text { total }\end{array}$ \\
\hline & \multicolumn{13}{|c|}{$k W h$} \\
\hline 1 & 53 & 91.86 & 339.83 & 443.43 & 567.39 & 559.14 & 538.02 & 534.28 & 323.1 & 238.11 & 88.68 & 61.24 & 3838.08 \\
\hline 2 & 59.25 & 103.82 & 268.09 & 388.75 & 532.43 & 568.37 & 521.36 & 467.91 & 256.57 & 156.08 & 54.35 & 33.01 & 3409.99 \\
\hline 3 & 110.06 & 116.17 & 301.39 & 423.27 & 581.42 & 577.68 & 500.98 & 536.37 & 242.75 & 210.40 & 76.87 & 64.14 & 3741.50 \\
\hline 4 & 80.18 & 141.26 & 343.82 & 341.66 & 554.85 & 573.30 & 456.23 & 566.98 & 291.12 & 209.58 & 68.54 & 41.85 & 3669.37 \\
\hline 5 & 43.09 & 95.941 & 293.51 & 388.46 & 506.45 & 554.77 & 484.77 & 445.11 & 226.49 & 143.58 & 47.50 & 26.83 & 3256.50 \\
\hline 6 & 133.87 & 151.21 & 323.48 & 420.78 & 513.26 & 515.96 & 478.60 & 487.82 & 288.28 & 216.06 & 79.15 & 53.73 & 3662.20 \\
\hline 7 & 68.58 & 122.42 & 336.39 & 401.59 & 529.83 & 520.85 & 478.86 & 504.93 & 302.84 & 206.95 & 77.09 & 47.17 & 3597.50 \\
\hline Average & 78.29 & 117.53 & 315.22 & 401.13 & 540.80 & 552.87 & 494.12 & 506.20 & 275.89 & 197.25 & 70.31 & 46.85 & 3596.45 \\
\hline
\end{tabular}

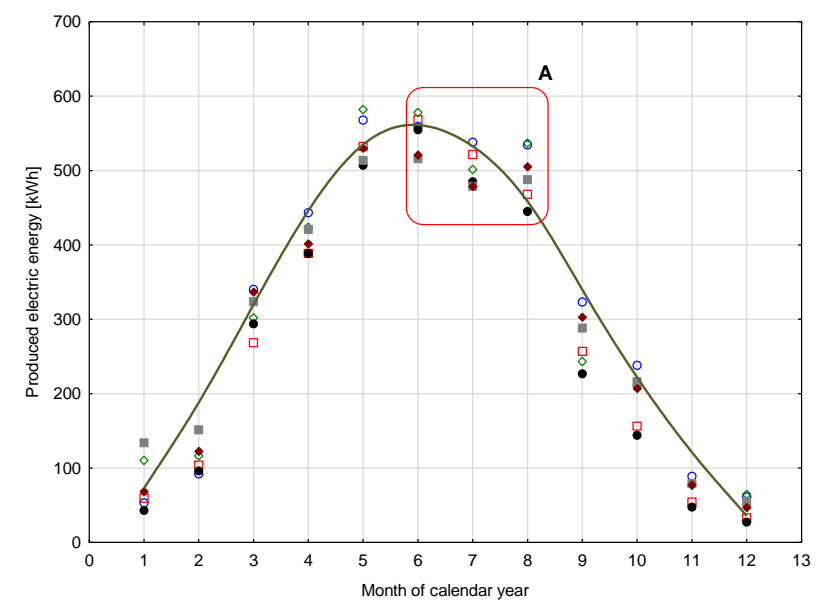

Fig. 9. Energy yields from all monitored installations and average value

The collected values characterise the whole yearly production of all solar installations. Average annual production of all installations amounted to $359.45 \mathrm{kWh}$, while installation with the highest average produced only $6.3 \%$ more energy, and the weakest as much as $10.44 \%$ less. When comparing monthly production of individual installations, it turns out that the results are not so beneficial. For example, in January, average production amounted to $78.29 \mathrm{kWh}$, which is not the month with the weakest production. The most efficient installation at that time produced as much as $58.48 \%$ more while the weakest by as much as $81.69 \%$ less. In the remaining months installations work more evenly.

Fig. 9 shows the yields from all monitored installations.

In an area bounded by a rectangle A (Fig. 9.) certain abnormality is visible. Namely, in July one of installations produces very little energy, with the production being large in the previous and subsequent months (Figure 10.). This indicates very large changes in insolation in a small area in a short time.

The presented change in production (Fig. 10.) depends on factors related to the properties of the atmosphere: its thickness, transparency and an instantaneous change in intensity of sunlight:

$E_{e m}=S \cdot G_{k} \cdot K_{A T} \cdot \eta$

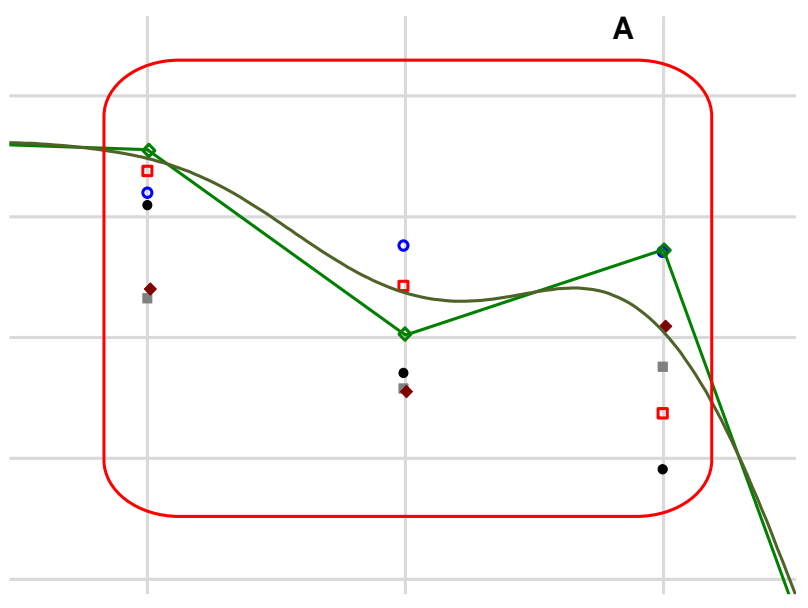

Fig. 10. Enlarged area A of Fig. 9.

where:

$E_{\text {em }}-$ production of electricity.

$\mathrm{S}$ - surface of solar modules.

$G_{k}$ - intensity of solar radiation.

$\eta$-- efficiency of photovoltaic modules

$K_{A T}$ - index of transparency and attenuation of the atmosphere (an indicator responsible for 'weather').

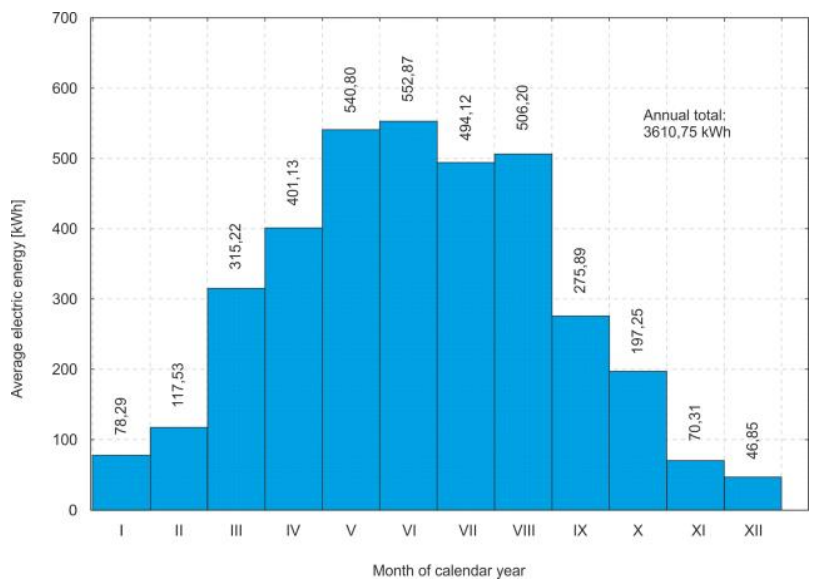

Fig. 11. Average production of electricity.

In the analysed case, the $K_{A T}$ indicator changes from 0.000974 in December to 0.00621 in May, and it is very 
similar for all installations, including "averaged" installation and "total" installation.

Fig. 11. Shows actual average electricity production obtained from all installations

Fig. 12. is a Pareto-Lorenz diagram that shows that the amount of energy delivered in three most favourable months is $44.3 \%$ and it is comparable with intensity of lighting on the atmosphere.

The six best months of the year provide $77.8 \%$ of annual production, which is also a better percentage than on the atmosphere.

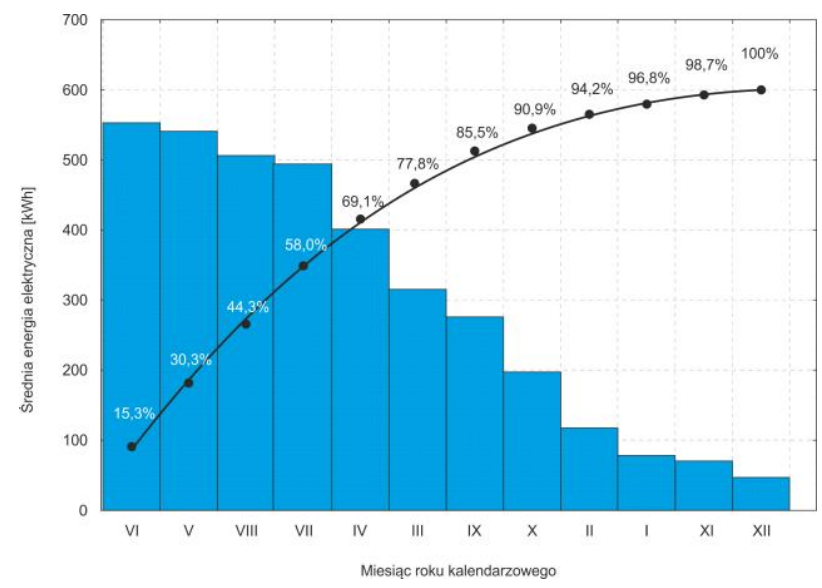

Fig. 12. Pareto-Lorentz analysis of insolation outside the atmosphere for particular months of the calendar year.

\section{Conclusion}

On the basis of the analysis, it can be concluded that low efficiency of photovoltaic installations is very important for energy production and is definitely greater than "efficiency" of solar radiation passing through the Earth's atmosphere ( $K_{A T}$ indicator). The obtained results of theoretical analysis related to planning energy yields of house installation differ only slightly from the results obtained during the operation of analysed installations, especially in relation to selected meteorological periods. Analysing the volume of energy production in selected ranges of the year, a significant mapping of theoretical conditions for total and average electricity production was obtained, both for the case of first and seventh installation. It should be noted that a certain uniqueness of electric energy yields in selected installations has been noticed, which may be related to short-term changes in the weather, including changes in transparency of the Earth's atmosphere. Presented analyses can be used to develop a model of disturbances in electricity production by home solar installation, and in the long run to diagnose and forecast electricity production.

\section{References}

1. A. Luque, S. Hegedus,. Handbook of Photovoltaic Science and Engineering. 2nd Edition (John Wiley \& Sons. Ltd., 2011)

2. H. Kanchev. D. Lu., F. Colas, V. Lazarov, B. Francois, IEEE Ind. Electron. 58, 10 (2011)

3. D.D. Wang, Sueyoshi. T., Appl Energ. 188 (2017)

4. J.H. Wong, M. Royapoor, C.W. Chan, Renew Sust Energ Rev. 58 (2016)

5. R. M. Swanson, Proc. 31st PV IEEE Orlando (2005)

6. J. Zhao, A. Wang, M.A. Green, Prog. Photovoltaics 7 (1999)

7. B. Norton, P.C. Eames, T.K. Mallick, J.D. Mondol, Y.G. Yohanis, Sol Energy 85, 8 (2011)

8. S. Guha, J. Yang, A. Banerjee, T. Glatfelter, Proc 2nd World Conf.\&Exhib. On PV Solar Energy Conversion. Vienna 6-10 July 1998 (1998)

9. M. A. Green, K. Emery, D. L. King, S. Igari, W. Warta, Prog. In Photovoltaics: Res. Appl. 12 (2004)

10. D. Ravikumar, B. Wender, T.P. Seager, M.P. Fraser, Appl Energ 189 (2017)

11. E. Skoplaki, J.A. Palyvos., Sol Energy 83, 5 (2009)

12. J.W. Spencer, Search 2, 172 (2017) 